\title{
The Primary Care Physician Workforce: Ethical and Policy Implications
}

\author{
Barbara Starfield, $M D, M P H^{1}$ \\ George E. Fryer, $J r, P b D^{2}$ \\ 'Johns Hopkins School of Public Health, \\ Baltimore, Md
}

${ }^{2}$ New York University School of Medicine, New York, NY

Conflicts of interest: none reported

\section{CORRESPONDING AUTHOR}

Barbara Starfield, MD, MPH

University Distinguished Professor

Johns Hopkins School of Public Health

624 North Broadway, Room 452

Baltimore, MD 21205

bstarfie@jhsph.edu

\begin{abstract}
PURPOSE We undertook a study to examine the characteristics of countries exporting physicians to the United States according to their relative contribution to the primary care supply in the United States.
\end{abstract}

METHODS We used data from the World Health Organization and from the American Medical Association Physician Masterfile to gather sociodemographic, health system, and health characteristics of countries and the number of international medical graduates (IMGs) for the countries, according to the specialty of their practice in the United States.

RESULTS Countries whose medical school graduates added a relatively greater percentage of the primary care physicians than the overall percentage of primary care physicians in the United States (31\%) were poor countries with relatively extreme physician shortages, high infant mortality rates, lower life expectancies, and lower immunization rates than countries contributing relatively more specialists to the US physician workforce.

CONCLUSION The United States disproportionately uses graduates of foreign medical schools from the poorest and most deprived countries to maintain its primary care physician supply. The ethical aspects of depending on foreign medical graduates is an important issue, especially when it deprives disadvantaged countries of their graduates to buttress a declining US primary care physician supply.

Ann Fam Med 2007;5:486-491. DOI: 10.1370/afm.720.

\section{INTRODUCTION}

M ost health systems employ foreign-educated health professionals. Such professionals make up more than one-quarter of the medical and nursing workforces of Australia, Canada, the United Kingdom, and the United States; even developing countries rely heavily on foreign physicians. ${ }^{1-3}$ Because the density of human resources for health is highly related, on average, to variation in maternal mortality, infant mortality, and mortality of children younger than 5 years, ${ }^{4}$ expatriation of foreign-trained health workers raises major ethical issues for countries already well-endowed with physicians.

In recent years as many international medical graduates (IMGs) as graduates of US medical schools (USMGs) have begun their training in family medicine residency programs in the United States. ${ }^{5}$ Because IMGs in all specialties move from residency programs into practice at rates very similar to those for USMGs, ${ }^{6}$ this trend toward importation of medical trainees has potential impact on family medicine, and thereby primary care, in the United States.

Our study examines the relationship between physician expatriation and characteristics of the expatriating countries. We used the American Medical Association (AMA) Physician Masterfile and data from the World Health Organization (WHO) to describe the quantity and specialty 
patterns (primary care vs subspecialty) of physicians migrating to the United States by characteristics of the country of undergraduate medical education and measures of health status of the population in the country they departed.

\section{METHODS}

We obtained data on IMGs practicing in the United States from the 2004 AMA Physician Masterfile. These data are verified by the Educational Commission for Foreign Medical Graduates (ECFMG), the organization that certifies applicants from other countries for residency training in the United States.

We first determined the number of physicians by country who had graduated from medical schools outside the United States. Residents and physicians known to be inactive or retired were excluded from each country's total. Canada, a major exporter of physicians to the United States, was not included in this study because of its reciprocal medical arrangements with the United States. Countries in which fewer than 50 physicians practicing in the Unites States had graduated from medical school were also eliminated from further analysis, leaving 85 countries eligible using only the AMA Physician Masterfile study criteria. Another 12 countries were excluded as a result of inadequate WHO data, as described below.

We grouped countries exporting IMGs according to whether the country added disproportionately to the primary care physician pool in the United States. Thirty-one percent constituted the line dividing 1 group from the other, as $31 \%$ is the overall percentage of US physicians who consider themselves to be practicing primary care. Thus, we classified the countries on the basis of the proportion of the US physician workforce $(31 \%)$ practicing primary care (family medicine, general practice, general internal medicine, and general pediatrics). This threshold differentiated countries whose IMGs added relatively more to the US primary care physician supply (31\% of US practicing physicians) than to other specialists (69\% of US practicing physicians). If $31 \%$ or more of a country's expatriated IMGs were in primary care practice, it was designated as a higher primary care supplier country. Lower primary care supplier countries were those from which less than $31 \%$ of their IMGs were practicing in primary care.

We then contrasted the 2 groups of countries with regard to (1) their gross national income per capita, (2) their own physician resources (population per physician), (3) indices of health status among the general population and children, and (4) rates of immunization. Measures 3 and 4 above are widely attributed to the adequacy of primary care, ${ }^{7}$ suggesting that emigration of that country's primary care resources may have been detrimental to the health status of its population. These data were extracted from the World Health Organization Statistical Information System (WHOSIS) and related links found at http://www.who.int/ whosis. Twelve countries were deleted from the study because of gross national income per capita data that either referred to years other than 2003, differed from the standard definition, or referred to only part of a country, leaving a total of 73 countries in the analysis. All variables describing countries pertain to the year 2003 except population and physicians, which apply to calendar year 2004 to coincide with data contained in the American Medical Association Physician Masterfile. Original data sources, definition of terms, and comments related to $\mathrm{WHO}$ data quality can be found at the WHOSIS Web site. Definitions used in characterizing countries from which physicians immigrated to the Unites States are as follows:

Gross national income (GNI) per capita (US\$): the sum of value added by all resident producers, plus any product taxes (less subsidies) not included in the valuation of output, plus net receipts of primary income (compensation of employees and property income) from abroad. GNI per capita is gross national income divided by mid-year population. GNI per capita in US dollars was converted using the World Bank Atlas method.

Under-5 mortality rate: probability of dying between birth and exactly 5 years of age expressed per 1,000 live births in the year 2003.

Life expectancy at birth: the number of years newborn children would live if subject to the mortality risks prevailing for the cross-section of population at the time of their birth in the year 2003.

Percentage of 1-year-old children immunized with 3 doses of diphtheria, tetanus toxoid, and pertussis (DTP3): the percentage of 1-year-old children who have received 3 doses of the combined diphtheria and tetanus toxoid and pertussis vaccine in calendar year 2003.

Percentage of 1-year-old children immunized with 3 doses of polio vaccine (polio3): the percentage of 1 year-old children who have received 3 doses of polio vaccine in calendar year 2003.

Percentage of 1-year-old children immunized with 1 dose of measles vaccine: The percentage of 1 -yearold children who have received at least 1 dose of measles-containing vaccine in calendar year 2003.

We contrasted the characteristics of the 38 countries with greater than $31 \%$ of their expatriated IMGs in primary care practice in the United States with the 35 with less than $31 \%$ using $t$ tests. Simple correlations were calculated for the associations of country 
characteristics and the percentage of primary care IMGs from the country. All analyses were done with SPSS, version 13.0 (SPSS, Inc, Chicago, Illinois).

\section{RESULTS}

IMGs from the 73 countries added 153,105 expatriate physicians, 58,502 (38\%) of whom were generalists. India provided more physicians $(34,746)$ and primary care physicians $(13,449$, or $39 \%)$ than any other country.

Table 1 characterizes the 2 groups of countries. Compared with the US physician workforce contribution to primary care practice $(31 \%)$, higher primary care supplier countries have about one-fifth the gross national income and physician-to-population ratios, averaging almost 3,000 to 1 ; about 4 times the mean ratio in the lower primary care supplier countries. That is, countries with large shortages of physicians disproportionately assist the United States in maintaining its primary care-specialist ratio.

Table 1 also indicates that the mortality rate among children younger than 5 years is almost 3 times greater, and the average life expectancy 7.5 years less in the higher primary care supplier countries than in the lower primary care supplier countries. The rate of death for children in the higher primary care supplier countries is about 50 per 1,000 , compared with 18 for the lower primary care supplier countries and 8 in the United States. Life expectancy in the higher and lower primary care supplier countries is 67 years and 74 years, respectively, compared with 77 years in the United States. Rates for receipt of all 3 types of immunization show similar disparities: lowest in the higher primary care supplier countries.

Existing sources of information on physician workforce do not contain information on the primary care-specialist balance in different countries. If all physicians in disadvantaged countries were practicing primary care, however, the countries would still merit designation as primary care health professions shortage areas according to the Health Resources and Services Administration (US) criteria. The number of primary care and all physicians migrating to the United States was much larger relative to physicians remaining in practice in the higher primary care supplier countries; several times greater than for nations exporting relatively more specialists to the United States. Table 2 shows that, for every area of the world, higher primary care supplier countries contributed a relatively greater percentage of the total number of physicians trained in the country. Except for Europe and Southeast Asia

Table 1. Characteristics of Countries Exporting a Higher and a Lower Percentage of Primary Care Physicians Than the Overall Percentage of Primary Care Physicians in the US Practicing Physician Pool, 2004

\begin{tabular}{|c|c|c|c|c|c|}
\hline & $\begin{array}{c}\text { Percentage of PCPS } \\
\text { Compared With US } \\
\text { Percentage* }\end{array}$ & Mean & $\begin{array}{l}\text { Standard } \\
\text { Error Mean }\end{array}$ & $t$ & $P$ Value \\
\hline \multirow{2}{*}{ GNI per capita, 2003, US\$ } & Higher & $2,994.7$ & 703.8 & -5.01 & $<.001$ \\
\hline & Lower & $14,946.9$ & $2,279.8$ & & \\
\hline \multirow[t]{2}{*}{ Population per physician, 2004, No. } & Higher & $2,924.8$ & 959.8 & 2.19 & .034 \\
\hline & Lower & 782.6 & 188.3 & & \\
\hline \multirow[t]{2}{*}{ Host country physicians per PC IMG, No. } & Higher & 69.2 & 11.6 & -4.39 & $<.001$ \\
\hline & Lower & 497.5 & 96.8 & & \\
\hline \multirow[t]{2}{*}{ Host country physicians per IMG, No. } & Higher & 28.3 & 4.8 & -3.66 & .001 \\
\hline & Lower & 129.7 & 27.2 & & \\
\hline \multirow[t]{2}{*}{ Under-5, 2003, mortality rate } & Higher & 49.6 & 8.3 & 3.62 & .001 \\
\hline & Lower & 17.7 & 2.9 & & \\
\hline \multirow[t]{2}{*}{ Life expectancy at birth, 2003, y } & Higher & 66.8 & 1.7 & -3.75 & $<.001$ \\
\hline & Lower & 74.3 & 1.1 & & \\
\hline \multirow[t]{2}{*}{ 1-year-old children-DPT3, 2003, \% immunized } & Higher & 83.7 & 2.8 & -2.28 & .026 \\
\hline & Lower & 90.9 & 1.4 & & \\
\hline \multirow[t]{2}{*}{ 1-year-old children-polio3, 2003, \% immunized } & Higher & 83.9 & 2.7 & -2.61 & .012 \\
\hline & Lower & 91.6 & 1.2 & & \\
\hline \multirow[t]{2}{*}{ 1-year-old children-measles, 2003, \% immunized } & Higher & 84.7 & 2.7 & -1.46 & .148 \\
\hline & Lower & 89.1 & 1.4 & & \\
\hline \multicolumn{6}{|l|}{ Note: Except for gross national income (2003). } \\
\hline \multicolumn{6}{|c|}{$\begin{array}{l}\mathrm{GNI}=\text { gross national income; } \mathrm{PC}=\text { primary care; IMG }=\text { international medical graduate; } \mathrm{DPT} 3=3 \text { doses of diphtheria-pertussus-tetanus toxoid vaccine; } \\
\text { polio3 = } 3 \text { doses of polio vaccine. }\end{array}$} \\
\hline
\end{tabular}




\begin{tabular}{|c|c|c|c|c|c|c|}
\hline Region & $\begin{array}{c}\text { Percentage of } \\
\text { PCPs Compared } \\
\text { With US } \\
\text { Percentage* }\end{array}$ & $\begin{array}{l}\text { No. of } \\
\text { Countries }\end{array}$ & $\begin{array}{l}\text { Ratio of IMGs to } \\
100 \text { Host Country } \\
\text { Physicians, } 2004\end{array}$ & $\begin{array}{l}\text { Per Capita } \\
\text { GNI, 2003, } \\
\text { uS\$ }\end{array}$ & $\begin{array}{c}\text { Physicians } \\
\text { per 100K } \\
\text { Population, } \\
2004\end{array}$ & $\begin{array}{l}\text { Physicians } \\
\text { (Including IMGs } \\
\text { in US) per 100K } \\
\text { Population, } 2004\end{array}$ \\
\hline \multirow[t]{3}{*}{ Africa } & Higher & 5 & 8.9 & 267 & 16.4 & 17.9 \\
\hline & Lower & 2 & 4.1 & 2,438 & 75.1 & 78.2 \\
\hline & Total & 7 & 7.8 & 774 & 30.1 & 32.5 \\
\hline \multirow[t]{3}{*}{ The Americas } & Higher & 16 & 14.0 & 4,073 & 146.4 & 166.9 \\
\hline & Lower & 7 & 1.4 & 2,825 & 198.8 & 201.6 \\
\hline & Total & 23 & 6.3 & 3,311 & 178.4 & 189.6 \\
\hline \multirow[t]{3}{*}{ Southeast Asia } & Higher & 3 & 6.4 & 520 & 47.4 & 50.4 \\
\hline & Lower & 2 & 2.2 & 1,113 & 19.1 & 19.5 \\
\hline & Total & 5 & 5.6 & 635 & 41.9 & 44.3 \\
\hline \multirow[t]{3}{*}{ Europe } & Higher & 8 & 1.6 & 8,167 & 392.3 & 398.6 \\
\hline & Lower & 15 & 1.4 & 20,185 & 297.0 & 301.2 \\
\hline & Total & 23 & 1.5 & 13,883 & 347.0 & 352.2 \\
\hline \multirow{3}{*}{$\begin{array}{l}\text { Eastern } \\
\quad \text { Mediterranean }\end{array}$} & Higher & 4 & 7.3 & 563 & 68.1 & 73.1 \\
\hline & Lower & 3 & 4.3 & 1,750 & 164.0 & 171.1 \\
\hline & Total & 7 & 6.1 & 1,043 & 106.9 & 113.4 \\
\hline \multirow[t]{3}{*}{ Western Pacific } & Higher & 2 & 10.9 & 778 & 84.3 & 93.5 \\
\hline & Lower & 6 & 0.2 & 4,396 & 166.9 & 167.2 \\
\hline & Total & 8 & 1.2 & 4,044 & 158.9 & 160.8 \\
\hline \multirow[t]{3}{*}{ Total } & Higher & 38 & 7.0 & 1,941 & 107.6 & 115.1 \\
\hline & Lower & 35 & 1.0 & 5,516 & 167.4 & 169.1 \\
\hline & Total & 73 & 3.6 & 3,837 & 139.3 & 144.3 \\
\hline
\end{tabular}

(with its large influence of India), higher primary care supplier countries had fewer physicians per population than countries contributing relatively more specialists to the US physician supply.

Table 3 provides the correlations between the actual percentage of each country's IMGs who are primary care physicians and the measures of health status and vaccination rates. All relationships are significant, particularly those involving health status. That is, the contribution of the countries to the US primary care physician workforce is highly correlated with measures of health deprivation in those countries: the greater the contribution, the poorer the health measures.

\section{DISCUSSION}

The limitations of this study relate to data availability and quality. The AMA Physician Masterfile is widely used in analyses of the US physician workforce, ${ }^{8-10}$ but inaccuracies have been found for certain categories of data. ${ }^{11,12}$ The most serious problem, sometimes associated with reporting lag, has involved physicians' actual practice locations, but this issue is not relevant for this study (which does not involve practice location). Data from the most underdeveloped countries have been difficult for the WHO to obtain (http://www.who. int/whosis); some member states still lack vital statistics registration, a problem for WHO calculation of life expectancy at birth and mortality of children younger than 5 years, which are variables used in this study. The number of physicians of different specialties is lacking from some of the most underdeveloped countries, limiting the extent to which we were able to assess physician
Table 3. Correlations With Percentage of Primary Care IMGs Who Attended Medical School in Countries Expatriating Physicians to the United States

\begin{tabular}{lcc}
\hline Need Heading & $\mathbf{r}$ & $\boldsymbol{P}$ \\
\hline Under-5 mortality rate, 2003 & .44 & $<.001$ \\
Life expectancy at birth (y), 2003 & -.44 & $<.001$ \\
\% Immunized, 2003, 1-year-old children, DPT3 & -.33 & .004 \\
\% Immunized, 2003, 1-year old children, polio3 & -.34 & .012 \\
$\%$ Immunized, 2003, 1-year old children, measles & -.28 & .018 \\
\hline DPT3 = 3 doses of diphtheria-pertussis-tetanus toxoid vaccine; IMGs = international \\
medical graduates; polio3 = 3 doses of polio vaccine.
\end{tabular}


drain in different types of health workforce in the countries. Moreover, the relatively small numbers of IMGs from individual countries would have limited the extent to which we could have categorized physicians into different subspecialties.

Overall, IMGs constitute $28.3 \%$ of all US primary care physicians, and this percentage has been increasing with time: $18.6 \%$ in $1980,21.7 \%$ in 1990 , and $27.5 \%$ in $2000 .^{13}$ The relationship between GNI per capita and contribution to the US primary care workforce is marked; countries whose IMGs contributed to maintaining the primary care physician supply in the United States were among the more economically disadvantaged and with very low physician-to-population ratios. The most impoverished, underdeveloped nation states of the African continent were a comparatively major source of primary care doctors to the United States, further diminishing their own capacity to meet the needs of their citizens. The magnitude of the physician drain is dramatically illustrated by Nigeria. There were 1,004 primary care physicians practicing in the United States who received their undergraduate medical training in Nigeria. The rate of mortality of children younger than 5 years there was 198 per 1,000 , and the average life expectancy 51 years. Nigeria recorded immunization rates of $25 \%, 39 \%$, and $35 \%$ for 1-year-old children for DPT3, polio3, and measles, respectively. The Nigerian population to physician ratio was greater than 3,700 to 1 .

The migration of physicians from underdeveloped countries to the United States is a serious concern, ${ }^{8,14-15}$ with economic ${ }^{16}$ as well as health implications. Medical schools in foreign countries are sometimes complicit in the strategy of wealthy countries to use foreign-trained physicians to meet the demands for health professionals, often encouraging their students to emigrate. ${ }^{17}$ In West Africa in particular, many medical school faculty who serve as respected mentors have had considerable experience in a developed country and regard migration as the mechanism for their students to realize their life goals. ${ }^{17}$ They take pride in their students' expatriation and may instruct students in English to better prepare them for examinations and clinical practice in the United States or United Kingdom. At the same time, the governments of some of the world's poorest countries have done little to retain their health care professionals by managing this out-migration with salary or status incentives, or by developing a private sector. ${ }^{18}$

Chen and Boufford ${ }^{19}$ asserted that "the plain truth is that medical systems in the United States and other wealthy countries are heavily dependent on imported workers" and reported that the demand for residency staffing exceeds the number of US graduates by $30 \%$. Enticement to import foreign-trained physicians to the
United States may even intensify, given the recent shift in opinion from impending physician surpluses here to forecasts of substantial future shortages. ${ }^{20}$ Deficits are projected by some to be as many as 200,000 physicians as early as the year 2020.

The results of this analysis join the issue of inequity in the maldistribution of world physician resources with the issue of needs and demands of the US health system. The US hospital system requires IMGs to fill its residency positions, and it also requires these physicians to maintain its primary care physician supply. Others have suggested that the US contribution to reducing the brain drain from developing countries could be overcome by training more physicians in the United States. ${ }^{21}$ Should more US-trained physicians enter practice without a change in current US physician workforce policies, however, the imbalance of specialty physicians to primary care physicians would be maintained or worsen and require even more importation of primary care physicians to make up for the falling supply in the United States.

The large influence of public policies on the size of the health workforce, even in the market-based context of the US health services system, was dramatically shown by Pond and McPake. ${ }^{22}$ The federal Medicare program subsidized hospital residency training starting in the late 1980s. Because hospital-based residencies are focused largely on training specialists, there followed a rising percentage of IMGs as first-year residents and an increase in the number of physicians licensed in the United States. Legislation in 1997 froze these subsidies; since then, the percentage of first-year residents who are IMGs has fallen. ${ }^{22}$

The impact of federal funding on primary care physician supply was also marked. Starting in 1976, support of primary-care-oriented residencies led to a marked increase in the number of physicians in family practice residences, only to be followed by a decline as support waned in recent years. ${ }^{23}$ Pond and McPake ${ }^{22}$ note that "confronted with labor shortages or lobbying for the health care industry, policy makers in various OECD [Organization for Economic Cooperation and Development] countries have shown a willingness to ease immigration, licensing requirements, or both, for internationally trained health workers."

The wisdom of US policy makers in recognizing and dealing with the impending crisis in the primary care workforce will determine the future course of health services in the country for decades to come. To avoid further compromising the resources of socially and economically disadvantaged countries, US workforce policy must respond to the challenge. Not only is current policy draining developing countries of their needed physicians, but it is particularly doing so with regard 
to vital primary care physician resources. There is good reason to be concerned about the wisdom and ethics of policies that have resulted in a continuing decline in the US primary care physician supply. Increased opportunities and incentives for training in and practice of primary care needs to be on the policy agenda.

To read or post commentaries in response to this article, see it online at http://www.annfammed.org/cgi/content/full/5/6/486.

Key words: Foreign medical graduates; primary health care; brain drain; US public policy/manpower

Submitted November 14, 2006; submitted, revised, February 22, 2007; accepted March 3, 2007.

\section{References}

1. Kingma M. [Migration patterns of health professionals]. Cah Sociol Demogr Med. 2005;45(2-3):287-306.

2. Hallock JA, Seeling SS, Norcini JJ. The international medical graduate pipeline. Health Aff (Millwood). 2003;22(4):94-96.

3. Whelan GP, Gary NE, Kostis J, Boulet JR, Hallock JA. The changing pool of international medical graduates seeking certification training in US graduate medical education programs. JAMA. 2002;288(9):1079-1084.

4. Anand S, Barnighausen T. Human resources and health outcomes: cross-country econometric study. Lancet. 2004;364(9445):1603-1609.

5. American Academy of Family Physicians. National Residency Matching Program. http://www.aafp.org/match. Accessed February 2007.

6. van Zanten M, Boulet JR, McKinley D, Whelan GP. Attrition rates of residents in postgraduate training programs. Teach Learn Med. 2002;14(3):175-177.

7. Starfield B, Shi L, Macinko J. Contribution of primary care to health systems and health. Milbank Q. 2005;83(3):457-502.

8. Hagopian A, Thompson MJ, Fordyce M, Johnson KE, Hart LG. The migration of physicians from sub-Saharan Africa to the United States of America: measures of the African brain drain. Hum Resour Health. 2004;2(1):17.
9. Fink KS, Phillips RL, Jr., Fryer GE, Koehn N. International medical graduates and the primary care workforce for rural underserved areas. Health Aff (Millwood). 2003;22(2):255-262.

10. Polsky D, Kletke PR, Wozniak GD, Escarce JJ. Initial practice locations of international medical graduates. Health Serv Res. 2002;37(4):907-928.

11. Freed GL, Nahra TA, Wheeler JR. Counting physicians: inconsistencies in a commonly used source for workforce analysis. Acad Med. 2006;81(9):847-852.

12. Rittenhouse DR, Mertz E, Keane D, Grumbach K. No exit: an evaluation of measures of physician attrition. Health Serv Res. 2004;39(5):1571-1588.

13. Physician Characteristics and Distribution in the US, 2002-2003 Edition. Chicago, IL: AMA Press; 2002.

14. Narasimhan V, Brown H, Pablos-Mendez A, et al. Responding to the global human resources crisis. Lancet. 2004;363(9419):1469-1472.

15. Martineau T, Willetts $A$. The health workforce: managing the crisis ethical international recruitment of health professionals: will codes of practice protect developing country health systems? Health Policy. 2006;75(3):358-367.

16. Kirigia JM, Gbary AR, Muthuri LK, Nyoni J, Seddoh A. The cost of health professionals' brain drain in Kenya. BMC Health Serv Res. 2006;6:89

17. Hagopian A, Ofosu A, Fatusi A, et al. The flight of physicians from West Africa: views of African physicians and implications for policy. Soc Sci Med. 2005;61(8):1750-1760

18. Martineau T, Decker K, Bundred P. "Brain drain" of health professionals: from rhetoric to responsible action. Health Policy. 2004;70(1):1-10.

19. Chen LC, Boufford JI. Fatal flows-doctors on the move. N Engl J Med. 2005;353(17):1850-1852.

20. Cooper RA, Getzen TE, McKee HJ, Laud P. Economic and demographic trends signal an impending physician shortage. Health Aff (Millwood). 2002;21(1):140-154

21. Mullan F. The metrics of the physician brain drain. N Engl J Med. 2005;353(17):1810-1818

22. Pond $B, M c P a k e ~ B$. The health migration crisis: the role of four Organisation for Economic Cooperation and Development countries. Lancet. 2006;367(9520):1448-1455.

23. Boulet JR, Norcini JJ, Whelan GP, Hallock JA, Seeling SS. The international medical graduate pipeline: recent trends in certification and residency training. Health Aff (Millwood). 2006;25(2):469-477. 